\title{
How to Use this Resource Pack
}

This pack of Case Studies is provided to supplement existing material available for the Foundation Programmes of Pre-Vocational Studies and GCSE courses.

The Case Studies are developed to the specification provided by the Joint Unit of BTEC and CGLI for the Foundation Programmes, although many also correspond to the requirements of GCSE.

Each Case Study has been written by teachers and lecturers from a wide variety of schools and colleges as a flexible resource for use both within GCSE courses and the Foundation Programmes. They are being used both as the basis of discrete courses and as teaching materials to enhance existing provision.

This pack contains a number of elements. There are 16 Case Studies, one for each module of the Foundation Programmes (see figure 2). For each Case Study, the following is provided.

\section{A Teacher's Guide}

This contains guidance on how to tackle the Case Study, a list of resources required, and detailed notes on the handling of each task.

\begin{abstract}
A Student's Guide
This material is copyright-free and may be freely photocopied. It contains individual task sheets for each step in the Case Study and additional resource sheets providing background information or worksheets.

The Case Studies may be used in any order and tutors may select freely which task sheets and/or resource sheets to use with their pupils, depending on the abilities of the students and the skills to be developed. Figure 3 shows the skills coverage in the Case Studies, according to the Foundation Programme skills checklist.
\end{abstract}

